\title{
Creating a learning climate: a South African study
}

Nasima Mohamed Hoosen Carrim

Johan Schutte Basson

Department of Human Resource Management, University of Pretoria, Pretoria, 0002, South

Africa

\begin{abstract}
Purpose - The purpose of the study was to ascertain whether there were differences in how one public and two private South African organizations created a learning climate.
\end{abstract}

Design/methodology/approach - This article is based on a survey and comparative analysis of specific departments in a chemical and gas company, an insurance company, and a semi-private state-owned organization (SPSOO) to establish dimensions that foster the creation of a learning climate.

Findings -The findings indicated that management support, autonomy and responsibility, time, the opportunity to develop, and guidelines to access information were pivotal in the creation of a learning climate and varied across organizations.

Research limitations/implications - The results indicated that variations across departments within each of these three organizations relating to employees' perceptions of a learning climate were not considered.

Practical implications - The study revealed that a learning climate can be created in different types of organizations through organizational, group and individual drivers. It further revealed that the strategy in creating a climate of learning should be aligned with the organization's structure, culture and goals.

Originality/value - This article makes a contribution to the literature on talent development in organizations as it indicates that different strategies can be utilized in successfully creating a learning climate in different types of organizations.

Key words - Drivers that foster a learning climate, Learning Climate Questionnaire, Dimensions of a learning climate; ANOVA, Friedman procedure

Article Type - Research article 


\section{Introduction}

"Learn or be extinct" is a popular cliché used by human resource development researchers, underscoring the importance of continuous learning for company survival (Sessa and London, 2006). Continuous learning within organizations is imperative for a young emergent economy such as South Africa that competes on a global level. With rapid advances in technology and customer demands for better products, the need to keep abreast of competitors is imperative (Sessa and London, 2006). In order to remain competitive, South African organizations have to make lifelong learning part of their organizational strategy. This implies that South African workplaces, both in the private and public sector, need to create a culture and climate of learning at all levels - namely, at the individual, group and organizational levels (Örtenblad, 2004).

The creation of a learning climate that adapts quickly to rapid changes in the environment enhances the sustainability of an organization and positions it as a forerunner compared with its competitors (Vera and Crossan, 2004). Learning is a multilevel process within organizations. The most significant learning takes place at the individual and group level. Some learning also occurs at the organizational level and results in changes in procedures, policies and practices which affect the culture and climate of the company (Rowe, 2010). The challenge for organizations, however, is to create and maintain a learning climate at the individual, group and organizational levels that will sustain their competitive advantage and also retain their talent mindset (Hellriegel and Slocum, 2011).

Scholars have examined the individual, group and organizational levels of learning within organizations from different perspectives. Research relating to learning at different levels has, for example, examined the role of leaders (Vera and Crossan, 2004), the changing perceptions of employees towards learning (Akdere and Schmidt, 2008), and the impact of organizational structure on the perception of learning climates (Örtenblad, 2004). Despite research being conducted into the creation of learning climates at individual, group and organizational levels (Akdere and Schmidt, 2008), few studies have compared organizations from the private and public service sectors in terms of their learning climates at individual, group and organizational levels (Örtenblad, 2004), possibly regarding the subject as not important enough to study. Given the paucity of such research, the rationale behind this article is the quest to find out which drivers at individual, group and organizational levels create a learning climate in three private and public service 
organizations, and how these drivers differ among private and public sector organizations. Considering that values, culture and climate within public enterprises are highly bureaucratic and rigid and differ vastly from those encountered in private organizations which have more flexible structures.

This article addresses this gap by proffering a distinction between a culture and climate of learning as well as how values in public and private enterprises differ. This is an exploratory study focusing on employees' perceptions of the learning climate within their respective departments in three different organizations at the individual, group and organizational levels. This is followed by the results obtained from the Learning Climate Questionnaire, a discussion of the research methodology and implications for future research, and conclusion.

\section{Literature review}

\section{Culture and climate}

Glisson (2000) points out that there is much confusion among scholars about what constitutes an organizational climate and culture, and that many researchers use the concepts interchangeably. Consequently, several definitions of culture and climate are discussed to highlight the differences between the two concepts.

Several researchers have defined the concept of organizational culture. Van Maanen and Schein (1979) define organizational culture as the shared beliefs, values and norms of behavior in the workplace. Rousseau (1990) defines culture as being composed of unconscious values, beliefs and assumptions, and includes the behavior of work groups, departments and workplaces. Researchers have variously defined culture from the perspective of individuals, social systems, behavior, perceptions, social structure and process (Glisson, 2000).

Organizational cultures are regarded as pivotal contributors to corporate learning as they shape values, beliefs and work systems that either enhance or obstruct knowledge acquisition and sharing (Slater and Narver, 1995). When an organization's culture is bureaucratic, employees will focus more on following procedures and obtaining approval for decisions, in this way stifling creativity and learning (Glisson, 2000). An organization's culture should therefore create an enabling environment where learning is encouraged and knowledge is easily accessible and disseminated. In addition, a learning culture should provide the 
organization with a leading edge with respect to its competitors (Slater and Narver, 1995).

Climate forms part of an organization's culture and has similarly been defined in various ways. Jones and James (1979) posit that an organization's climate is taken as the employees' perceptions of their work environments. This implies that different organizations will have different climates which are created through the meanings workers attach to the workplace. Climate in fact emerges from the organizational context which employees believe is imperative and influential in their work. In this regard, climate is viewed as an important part of the organization as various perceptions, beliefs and meanings result in individual perceptions, interpretations and expectations of the organizational environment that affects behavior (Schein, 1990). A corporate learning climate therefore relates to the perceptions workers have of the organization's environment that either impedes or encourages learning and influences corporate performance (Slater and Narver, 1995). Mikkelsen and Grønhaug (1999) point out that learning cultures and learning climates are related concepts and impact individual, group and organizational learning.

The focus of this article is the learning climate in three South African organizations. Researchers have advanced many definitions of a learning climate. However, for the current article, Schein's (1990) definition will be used where climate is regarded as a multidimensional construct which is a collection of the perceptions of all employees within an organization and is a reflection of the enterprise's culture.

\section{Culture, climate and organizational value systems}

Values are defined as "the criteria people use to select and justify action and to evaluate people (including the self and events) (Schwartz, 1992, p. 1). Values influence behaviour to the extent that employees make choices consistent with what is significant to all organizational members in their respective organizations (Rokeach, 1973). Therefore, corporate culture is a function of deeply rooted shared values and employees' behaviour which is adaptable and is based on the climate of the workplace at the individual, group and organizational levels ( Slater and Narver, 1995). Within organizations value systems that encourage continuous learning influence employee behaviour toward innovation and competitiveness (Mikkelsen and Grønhaug, 1999).

Learning organizations emphasizes the role of value systems that encourage continuous learning and result in employees endeavoring toward higher performance 
in order to remain competitive (Slater and Narver, 1995). Thus, organizational learning cultures are characterized by values that encourage acquiring, distributing and sharing of information for the improvement of the workplace (Slater and Narver, 1995). These values are based on norms relating to creativity and innovation, human resource systems that encourage continuous worker development and managers that support change and innovation (Bates and Khasawneh, 2005). These organizational cultural value systems in turn encourage workplace climates related to acquiring and applying new knowledge and skills and valuing innovation and long-term performance improvement through learning (Bates and Khasawneh, 2005).

Learning cultures, climates and values within public and private sector organizations differ however. Within private organizations change is accepted and therefore learning, improvement and innovation is embraced (Kernaghan et al., 2005). In highly bureaucratic structures such as the public sector, risks and mistakes are avoided and in this way the status quo is maintained (Finger and Brand, 2001). Public organizations are dominated by government parties who through legislation influence managers to be authoritarian, coercive and expect workers to follow rules and procedures which constrain work processes (Finger and Brand, 2001). In contrast, private enterprises are more often led by managers who foster commitment, flexibility and creativity within their employees and in this manner encourage learning (Kernaghan et al., 2005). Within the public service the focus is often on the needs of the organization itself but in the private sector the focus is on providing quality service to the client. The culture of public organizations is also rarely based on consultation, cooperation and consesus, unlike in the private sector (Finger and Brand, 2001). When enterprises within the public sector have embraced a non-bureaucratic structure, then learning, innovation and creativity become pivotal in changing values, the culture and climate of the organization (Kernaghan, Marson and Borins, 2005).

We therefore suggest that at the individual, group and organizational levels, value systems within a particular workplace influence the extent to which learning takes place as espoused by the culture and climate of the organization and will vary across organizational contexts.

\section{Drivers that foster a learning climate}

The literature indicates that the key to the success of a learning climate lies in the fact that the most important drivers at the organizational, group and individual levels 
should be identified and implemented in an integrated and sustainable manner (Falconer, 2006).

\section{Drivers at the organizational level}

Martin and Brun (2009) state that learning at the organizational level takes place for various reasons. First, learning takes place in order to introduce development that will bring about changes in organizational behavior and patterns of actions which result in enhanced organizational performance and competitiveness. Second, organizations implement strategies, ethics, policies and rules to improve the learning culture and climate. Third, organizations introduce teams to enhance collaboration.

In order to promote learning, managers, and top management in particular, have to be committed to creating a culture of learning (Abu Khadrah and Rawabdeh, 2006) by establishing a network of working relationships that extend over all company functions (Swift and Hwang, 2008) and allowing employees to participate in decisions relating to policy-making (Jamali et al., 2006). Management support forms an important component of a learning climate at the organizational level.

\section{Drivers at group level}

One important driver identified at the group level is team approach, referring to the willingness of team members to support one another and to share information and team leadership, which plays an important role in fostering an environment of learning (Nyhan et al., 2004).

Secondly, group learning which is another driver within a team is vital in achieving learning at the organizational level. This occurs when individual learning is transformed into organizational knowledge. This leads to team effectiveness (Abu Khadrah and Rawabdeh, 2006) and innovative and creative solutions to problems, as ideas, tacit and explicit knowledge are shared, action is taken, and a common set of meaning is developed (Cunningham and Illes, 2002).

\section{Drivers at the individual level}

In organizations, learning begins and ends with the individual employee, and not with the organization, as individuals create, acquire, organize and spread knowledge from others into organizational processes and systems (Swift and Hwang, 2008). The 
willingness to learn and become involved in learning has to come from each individual employee, because without individual commitment learning will not take place, no matter how management might try and sell their vision and direction (Swift and Hwang, 2008). Therefore, the qualities individuals need in order to learn are commitment, internal motivation and eagerness.

Over the years, individual and organizational learning have been much debated. Some researchers believe that only individuals and not organizations learn, while others feel organizations do indeed learn (Örtenblad, 2004).

This article endorses Rowe's (2010) viewpoint regarding learning at the individual, group and organizational levels; for example, an employee learns at the individual level as collaboration with people from within and outside the organization takes place; groups learn as their team engages in achieving goals; and the organization learns as it obtains feedback from the environment and expects further change. At all levels, learning is transformed into new procedures, measures and goals.

\section{Empirical research}

Surprisingly, not much empirical research has been conducted on employees' perceptions regarding the creation of a learning climate at the individual, group and organizational levels. However, research has been conducted into climate and various outcomes at the individual, group and organizational levels, for example leader behavior, turnover intentions, job satisfaction and organizational performance (Patterson et al., 2005). Cunningham and Illes (2002), for example, conducted a study on a financial services organization in the United Kingdom by means of a survey and case study approach. The aim was to ascertain the extent of individual, group and organizational learning in the organization and management's role in fostering a learning climate. The results of the study indicated that, while managers were committed to encouraging employees to learn, they did not take the initiative to provide such opportunities.

Given the lack of research into employees' perceptions of the creation of a learning climate at the individual, group and organizational levels, it was decided to formulate the following two hypotheses: 
H1: More drivers are significant in the creation of a learning climate in private companies than in public-owned service organizations.

$\mathrm{H} 2$ : Certain drivers are more important than others in creating a learning climate at the individual, group and organizational levels.

\section{Methodology}

Sample

To evaluate perceptions relating to the learning climate, one questionnaire was included in the study. Data was collected from non-managerial employees in two private-sector and one public-service organizations regarding their perceptions of the existence of a learning climate within their respective organizations. A total of 431 questionnaires were distributed in the three organizations. The number of employees surveyed in each organization varied and so too did the work they engaged in. In addition, the employees surveyed in the research described in the current article did not represent the work conducted by the rest of the employees in their respective organizations. The employees surveyed represented a small percentage of a department in an organization. The chemical and gas company employed 25000 workers. Permission was given to circulate only 300 questionnaires to nonmanagerial staff in the marketing operations and chemical manufacturing departments. The insurance company employed 11000 people in South Africa. Permission was given to conduct the survey in two call centers consisting of 82 callcentre operators. The semi-private state-owned organization (SPSOO) consisted of over 19000 employees but permission was received to conduct the survey on clientservice personnel consisting of 49 staff members in one department only. In total, 340 questionnaires were completed and returned. The individual response rate for the chemical and gas company; the insurance company and the SPSOO were 70 percent, 100 percent and 86 percent respectively. The chemical and gas company had both a bureaucratic, hierarchical structure and an individualized culture. The insurance company had a flat, team-based organizational structure. The SPSOO had a bureaucratic hierarchical structure and autocratic management culture.

\section{Instrument}

Perceptions relating to the existence of a learning climate were examined using the Learning Climate Questionnaire (LCQ) developed by Bartram et al., (1993). The 
LCQ measures respondents' perceptions of seven learning-climate dimensions consisting of ten items each. The dimensions address organizational principles such as workplace learning and practical measures to increase learning and development. The LCQ contains 70 items and uses a five-point Likert scale with anchors from "always true" to "never true". The instrument includes seven learning-climate dimensions to measure individual, group and organizational dimensions. The reliability of the subscales ranged between .73 and .87 and the overall reliability of the Learning Climate Questionnaire is .81 (Mikkelsen and Grønhaug, 1999).

\section{Learning Climate Drivers (LCQ drivers)}

- Management relations and style (Ma) high scores indicate a perception of managers being supportive. An example is "I can discuss my work with my immediate manager and get constructive comments."

- Time (Ti) high scores indicate employees' perception that they have adequate time to do their work and learn new things. An example is "In some parts of the job there is enough time to keep up with changes."

- Autonomy and responsibility (Au) refers to the employees' freedom to take responsibility regarding work arrangements and to initiate action in the workplace. An example is "I feel free to make my own decisions".

- Team style (Te) high scores indicate perceptions of learning from expert colleagues. An example is "If we ask each other for help, it is given."

- Opportunity to develop (Op) high scores indicate a perception that there are opportunities to learn new things and do a variety of tasks at work. An example is "There are lots of different ways to learn new jobs here."

- Guidelines (Gu) to do the job refers to accessing information and guidelines relevant to the job, as well as information on formal and non-formal coaching, mentoring and training. An example is "There are more written guidelines on how to do my job available for me to refer to."

- Alignment or contentedness (Co) describes a general feeling of satisfaction with the workplace climate. An example is "Others moan about things without doing anything." 
Research to test the validity of the LCQ had been conducted outside Britain where the questionnaire was originally tested. For example, Mikkelsen and Grønhaug (1999) tested the discriminant, convergent and predictive validity of the LCQ in two Norwegian cities. The analysis of their data revealed that the LCQ did not produce the same dimensionality as found by Bartram (1993) in Britain. The researchers also discovered conceptual ambiguities in the LCQ and recommended that the dimensions had to be conceptually clarified, and that the dimensionality of the LCQ should be tested by other researchers.

The main criticism labeled against the use of the Learning Climate Questionnaire in the current research was that it focussed on the learning climate as a structure which affected the learning behavior of employees. For example, the questionnaire asked employees about the amount of time and autonomy they experienced in their work. However, the questionnaire did not address the informal learning experienced by employees, which could have influenced the autonomy the workers encountered in their workplaces. Organizational structure is, however, still relevant to the learning climate as time and autonomy may be perceived as part of the norms and values of the organization relating to the liberty employees should be allowed with regard to learning activities (Poell and Van Moorsel, 1998). The LCQ was, however, used in the current article, as it is a robust instrument that can be adapted across different countries and cultures (Mikkelsen and Grønhaug, 1999).

\section{Data analysis}

The responses to the LCQ were tabulated for each organization to determine the extent to which respondents perceived their respective workplaces as having a learning climate. Responses were also tabulated comparing the three organizations to determine the differences relating to the creation of a learning climate. Higher scores indicate differences in the drivers applicable to each organization in creating a learning climate. Means and standard deviations were calculated for the LCQ scales for all three organizations and the seven LCQ dimensions described above. Scores were evaluated for differences within the three organizations using the Friedman Analysis of Variance test (ANOVA). Scores were also evaluated for differences among the organizations on the seven drivers using ANOVA. 
The respondents for the study were 65 percent male and 35 percent female. The majority (102) were between 31-40 years old, had completed high school (128), an associate degree (49) or an undergraduate degree (20). The majority of the respondents (98) had been with their current company for $2-5$ years.

The Friedman test was conducted to determine the differences within each organization pertaining to the seven drivers. Table 1 shows the means and standard deviations for the LCQ drivers for all three organizations generated from the Friedman test. The means for the organizations ranged from 4.1 for the chemical and gas company on the management relations and style scale to 2.7 for the SPSOO on the team style scale. Mean values that were identical were assigned the same characters (for example, a, b, c, d, e), which implied that the dimension in that instance did not contribute significantly towards the creation of a learning climate. For example, in the SPSOO, management and team styles both had the same mean values (2.7) (indicated by the letter "a" in this case). This implied that management and team styles were less significant in creating a learning climate. The results suggested that larger differences existed among the mean values of dimensions within the chemical and gas and the insurance companies $(\mathrm{p} \leq 0.01)$ than the SPSOO. This result indicates that most of the drivers contribute significantly towards the creation of a learning climate within the chemical and gas and insurance companies compared with the SPSOO, which supports H1.

\section{Insert table I here}

A two-way ANOVA was conducted to determine if there were differences across the three organizations relating to the seven drivers. Table 2 indicates there were significant differences in mean values among the three organizations $(p \leq 0.01)$ along certain drivers. There were differences among mean values relating to management relations and style across the three organizations. There were also differences in mean values across the three organizations relating to employees being provided with the autonomy and responsibility in conducting work. Significant differences in mean values across the three organizations were also noted regarding employees having guidelines to accessing information. The results indicated that these three drivers 
from among the seven drivers were more significant in the creation of a learning climate which supports $H 2$.

\section{Insert table 2 here}

\section{Discussion}

The results indicated variations within organizations relating to the creation of a learning climate. The results suggest that the chemical and gas company had the most variation among the drivers followed by the insurance company and thereafter SPSOO. One possible explanation for the variation among drivers in the chemical and gas company could be attributed to its not operating in isolation, but having competitors in the global market. Although the chemical and gas company had a hierarchical and bureaucratic structure, competing with overseas markets to produce innovative products require the organization to adopt a strategy relating to a culture and climate of learning and experimentation (Marsick and Watkins, 2003). This suggests that the external environment and strategy of the organization played a far bigger role in the creation of a learning climate than the structure of the organization. Another possible reason could be that the survey was conducted on chemical engineers and the marketing employees who needed to learn continuously in order to keep abreast of developments in their fields (Örtenblad, 2004). This could be important because both groups were professionals who enjoyed autonomy and flexibility in terms of how they conducted their work, which resulted in them adopting innovative ways to keep abreast of changes within the external environment.

There was less variation among variables in the insurance company. This could be important for future research on the learning climate since the insurance company had a flat organizational structure and was dominated by a team orientation. In this article, a flat team structure does not imply that employees regard it as more of a learning climate than employees in a hierarchical structure with an individualistic orientation. One possible explanation for the call centre agents in the insurance company surveyed reporting less variation in drivers compared to engineers in the chemical and gas company could be that they operated in a multi-tiered environment in handling client queries. If they could not handle client queries at their level, the calls were forwarded to product engineers, developers and highly skilled technical staff. Call centre agents had limited product knowledge and unlike the engineers and 
developers, needed to focus less on informal learning. Another explanation could be that the organization was competing locally and that less rapid product innovations occurred in this industry and its external environment than in the chemical and gas company, resulting in a different strategy compared with the latter company.

The SPSOO was a government institution characterized by a hierarchical structure and bureaucracy. Variation among variables was minimal. This had important implications for future research relating to the learning climate as employees operated in a structured environment where work was routine and deviations were minimal. One explanation could be that the introduction of innovative products was implemented by strategic managers and not by lower-level employees (Rowold et al., 2008). Another could be that, while employees learned from clients on how to improve systems and procedures, managers might not have provided a platform for such discussions as supervisors might not have the power to implement such major changes (Cunningham and Illes, 2002).

Although both the chemical and gas companies and the SPSOO had hierarchical bureaucratic structures, organizational strategy, employee autonomy and the external environment played a significant role in workers' perceptions of learning climates in their respective organizations (Örtenblad, 2004). Again, a possible explanation is that processes, procedures and policies changed at a slower pace in the department surveyed in the SPSOO than the pace of the changes in the departments in the chemical and gas and insurance companies. Employees therefore reported the SPSOO as having less of a learning climate than the other two organizations.

In all three organizations, employees considered management relations and style as imperative in creating a learning climate, although management style differed in all three organizations. This finding was consistent with studies where support from management resulted in the creation of a learning climate (Akdere and Schmidt, 2008; Nyhan et al., 2004). This finding also indicated that learning was regarded as a daily activity and that management could both support and encourage it through their interaction and style, or completely hamper it (Akdere and Schmidt, 2008). Management support for learning was the highest in the chemical and gas company. This could be attributed to an enabling culture within the organization. While management support for learning existed in the SPSOO, it was less than in the other two organizations. This could be attributed to the fact that there were fewer 
opportunities to implement new systems and products as such decisions were taken by top management and adhered to imperatives set by local government.

Autonomy, responsibility and guidelines to do the job were also perceived by employees as imperative in creating a climate of learning. This implies that employees needed the freedom to innovate and take decisions without negative repercussions. Employees also needed to know where they could access formal and informal training. In the chemical and gas company, and to a lesser extent in the insurance company, employees had the freedom to be innovative and had greater access to formal and informal training. Again, this may be attributed to the external environment and strategy of the organizations. Employees in SPSOO perceived less autonomy than in the chemical and gas and insurance companies and engaged in mostly formal training relating to their jobs. Again, this could be attributed to the type of work they were engaged in, namely service to the public and being in an environment where decision-making was in the hands of top management.

There were less significant differences among drivers relating to time, team style, opportunity to develop and contentedness among the three organizations. Employees in the chemical and gas company perceived having more time, opportunities and working in teams as a way of enhancing learning compared with employees in the insurance company and SPSOO. Again, this could be attributed to the nature of the job employees were engaged in, organizational strategy, culture and management support.

\section{Recommendations for future study}

The results obtained from this exploratory study provide some evidence of how perceptions vary in the creation of a learning climate. However, the results should be viewed taking into account the limitations of the study. These include the small sample size of only three departments in three organizations, the type of sample (purposive in terms of choosing companies and convenience for collecting data from workers), the cross-sectional nature of the survey and other factors impacting on the individuals themselves. To address these limitations and further enhance the findings, future research should address several important areas. Firstly, researchers should collect data from more organizations in the private and public service sectors so as to increase the sample size of employees at various levels and working in different departments. Having a larger sample size, employees from different organizational 
levels and more organizations with different structures and strategies would increase the accuracy of the results and provide a better understanding of employees' perceptions of a learning climate. Secondly, future studies should focus on conducting follow-up interviews in addition to conducting the survey with employees at different levels to increase the validity of the study through triangulation. Thirdly, future research could fruitfully focus on a longitudinal study in measuring changes in perceptions relating to the creation of a learning climate. Fourthly, researchers could in the future conduct a qualitative study relating to the learning climate within private and public organizations. Finally, factors other than those tested in the LCQ could affect employees' perceptions, and another climate questionnaire could be used in conjunction with the LCQ.

\section{Recommendations for practice}

The results of the study provide useful information that could be used to inform the perceptions of employees regarding the creation of a learning climate. Since this was an exploratory study based on three departments of three organizations, the recommendations may not apply to all organizations. One recommendation is that organizations striving to establish a learning climate should establish a culture of learning through organizational practices, policies and procedures even when not competing in the global arena. A second recommendation is that to encourage workers to perceive a learning climate, they should be given adequate time to explore various learning opportunities within the organization. In such instances, workers could be rotated within different workstations in order to create these opportunities where they can learn different tasks from experts in diverse areas. Managers should embrace a culture and climate of learning and provide an enabling learning culture which in turn will result in creating perceptions of a learning climate.

\section{Conclusion}

Employee perceptions about the creation of a learning climate in private and public sector organizations vary to a great extent. Even within private-sector organizations such as the gas and chemical company and SPSOO, which had the same organizational structure, the perceptions of workers differed about the creation of a learning climate. For example, in the chemical company, formal qualifications, teamwork, the opportunity to be innovative, learning daily on the job and working in 
global markets were the strategies adopted. Employees in the SPSOO had fewer formal qualifications, worked less in teams and did not compete in the global market, resulting in workers having a different perception of their learning climate than employees in the chemical and gas and insurance companies. The findings indicate that management support, autonomy and responsibility, time, opportunity to develop and guidelines for accessing information are pivotal in the creation of a learning climate and vary across organizations.

\section{References}

Abu Khadra, M.F. and Rawabdeh, A.I. (2006), “Assessment of development of the learning organization concept in Jordanian industrial companies", The Learning Organization, Vol. 13 No. 5, pp. 455-474.

Akdere, M. and Schmidt, S.W. (2008). "Employee perceptions of an organization's learning climate: Effects of employee orientation training”, paper presented at the Academy of Human Resource Development International Research Conference in the Americas, Panama City, Florida.

Bartram, D., Foster, J., Lindley, P. A., Brown, A.J. and Nixon, S. (1993), The Learning Climate Questionnaire (LCQ): a user's guide, Employment Service and Newland Park Associates Limited, Oxford.

Bates, R. and Khasawneh, S. (2005). "Organizational learning culture, learning transfer climate and perceived innovation in Jordanian organizations", International Journal of Training and Development, Vol. 9 No 2, pp. 96-109.

Cunningham, P. and Illes, P. (2002). "Managing learning climates in a financial services organisation”, Journal of Management Development, Vol 21 No. 6, pp. 477492.

Falconer, L. (2006), "Organizational learning, tacit information and e-learning: a review", The Learning Organization, Vol. 13 No. 2, pp. 140-151. 
Finger, M. and Brand, S.B. (2001), "The concept of the 'Leaning Organization' applied to the transformation of the public sector, in Easterby-Smith, M., Burgoyne, J. and Araujo, L. (Eds.), Organization learning and the learning organization. Developments in theory and practice, Sage Publications, London, pp. 130-156.

Glisson, C. (2000), "Organizational climate and culture”, in Patti, R.J. (Ed.), The Handbook of Social Welfare Management, Sage Publications, Thousand Oaks, Ca, pp. 195-218

Hellriegel, D. and Slocum, J.W. (2011), Organizational Behavior, $13^{\text {th }}$ ed., Thomson Higher Education, Mason, Ohio.

Jamali, D, Khoury, G. and Sahyoun, H. (2006), "From bureaucratic organizations to learning organizations", The Learning Organization, Vol. 13 No. 4, pp. 337-352.

Jones, A. P. and James, L.R. (1979), "Psychological climate: dimensions and relationships of individuals and aggregated work environment perceptions". Organizational Behavior and Human Performance, Vol. 23, pp. 201-250.

Kernaghan, K., Marson, B. and Borins, S. (2005), The new public organization, The Institute of Public Administration of Canada, Toronto, Ontario.

Marsick, V.J. and Watkins, K.E. (2003), "Demonstrating the Value of an Organization's Learning Culture: The Dimensions of the Learning Organization Questionnaire", Advances in Developing Human Resources, Vol. 5 No. 2, pp. 132151.

Martin, A. and Brun, R. (2009), “Applying Organizational Learning to Enterprise Knowledge Maturing”, in 9th International Conference on Knowledge Management, I-KNOW '09 I-KNOW,09 and I-SEMANTIC' 09, Proceeding of the international conference in Graz, Austria, pp. 39-50.

Mikkelsen, A. and Grønhaug, K. (1999), "Measuring Organizational Learning Climate : A Cross-National Replication and Instrument Validation Study Among 
Public Sector Employees", Review of Public Personnel Administration, Vol. 19, pp. $31-44$.

Nyhan, B., Cressey, P., Tomassini, M., Kelleher, M. and Poell, R. (2004), "European perspectives on the learning organisation", Journal of European Industrial Training, Vol. 28 No. 1, pp. 67-92.

Örtenblad, A. (2004), “The learning organization: towards and integrated model”. The Learning Organization, Vol. 11 No. 2, pp. 129-144.

Patterson, M.G., West, M. A., Shackleton, V.J., Dawson, J.F., Lawthom, R., Maitlis, S., Robinson, D. and Wallace, A.M. (2005), "Validating the organizational climate measure: links to managerial practices, productivity and innovation", Journal of Organizational Behavior, Vol. 26, pp. 379- 408.

Poell, R. and Van Moorsel, M. (1998), Organizing work-related learning Projects: a Network approach. Unpublished $\mathrm{PhD}$ dissertation, University of Nijmegen, Nijmegen.

Rokeach, M. (1973), The nature of human values, The Free Press, New York.

Rousseau, D.M. (1990), “Assessing organizational culture: The case for multiple methods", in Schneider, B. (Ed.), Organizational climate and culture, Jossey-Bass, San Francisco, pp. 153-192.

Rowe, E. (2010). "Looking at Extension as a Learning Organization", Journal of Extension, Vol. 48 No. 4, pp. 110-120.

Rowold, J., Hochholdinger, S. and Schilling, J. (2008), "Effects of career-related continuous learning: a case study", The Learning Organization, Vol. 15 No. 1, pp. 45 $-57$. 
Schein, E. H. (1990), “Organizational culture”, American Psychologist, Vol. 45 No. 2 , pp. 109-119.

Schwartz, S.H. (1992), "Universals in the content and structure of values: Theoretical advances and empirical tests in 20 countries", in Zanna M.P. (Ed.), Advances in experimental social psychology, Academic Press, San Diego, Ca, pp. 1-65.

Sessa, V. I. and London, M. (2006), Continuous learning in organizations. Individual, group and organizational perspectives, Lawrence Erlbaum, Associates Inc, New Jersey.

Slater, S.F. and Narver, J.C. (1995), "Market orientation and the learning organization", Journal of Marketing, Vol 59 No.3, pp. 63-74.

Swift, P.E. and Hwang, A. (2008), "Learning, dynamic capabilities and operating routines", The Learning Organization, Vol. 15 No. 1, pp. 75-95.

Van Maanen, J. and Schein, E.H. (1979), "Toward a theory of organizational socialization", in Staw B.M. and Cummings L.L. (Eds.), Research in Organizational Behavior, JAI Press, Greenwich, CT, pp. 209-264.

Vera, D. and Crossan, M. (2004), "Strategic Leadership and Organizational Learning", Academy of Management Review, Vol. 29 No. 2, pp. 222-240. 